\title{
Improving the Quality of Healthcare by Using Information Technology System in the Hospitals of Yemen
}

\author{
Nuha Abdullah Nagi Albokai*, Lin Liu, Ali Alragawi, Ahlam Albokai \\ Hefei University of Technology, Hefei, China \\ Email: ^2016nuha@gmail.com
}

How to cite this paper: Albokai, N.A.N., Liu, L., Alragawi, A. and Albokai, A. (2019) Improving the Quality of Healthcare by Using Information Technology System in the Hospitals of Yemen. Open Journal of Business and Management, 7, 728-754. https://doi.org/10.4236/ojbm.2019.72049

Received: March 6, 2019

Accepted: April 6, 2019

Published: April 9, 2019

Copyright (c) 2019 by author(s) and Scientific Research Publishing Inc. This work is licensed under the Creative Commons Attribution International License (CC BY 4.0).

http://creativecommons.org/licenses/by/4.0/

\begin{abstract}
The health sector is considered one of the most important sectors in the application of the IT system because of its impact on improving the quality of services provided. In this study, we identify the impact of using the IT system in improving the quality of health care in Yemen hospitals (Sana'a capital city). In order to achieve this goal, we designed a questionnaire for hospital staff in the capital city of Sana'a appointed by eight randomly selected hospitals divided into three public hospitals and five private hospitals. The questionnaire consisted of 36 paragraphs with detailed questions answered by 407 employees. We identify four dimensions for attitudes about healthcare IT adoption: time, effort, cost, safety. We find positive correlations between healthcare IT adoption and improvements in quality of care across all four dimensions. In conclusion, our study highlights a number of recommendations, including the importance of enhancing the effectiveness of the database to provide health services with high efficiency, the need to adopt the information technology system in all health sectors and attention to the maintenance of devices and websites and challenge them continuously, attracting healthcare professionals specialized in the use of computer systems and rehabilitation of hospital staff by holding training courses. Our study also points to the importance of linking all sections of the hospital in one network system so that communication between them internally and work to link hospitals in the capital city of Sana'a with an external network to facilitate the exchange of information between them.
\end{abstract}

\section{Keywords}

Health Care, Information Technology, Hospitals in Yemen 


\section{Introduction}

With the tremendous progress in information technology and the invasion of the world in the so-called globalization era emerged terminology adopted the evolution in the use of digital technologies and computer devices employed by the person for his benefit and benefit in the application of his life, this helps IT improve service delivery procedures, facilitating and facilitating the work and transactions provided by the hospitals to its auditors and achieving communication with them, where it is possible to provide data and information to them transparently and clearly and offer models and procedures to provide services better, which facilitates the movement of dealing with employees better.

We all know that the IT system plays an important role in all areas and activities in our daily life. The health care sector has been taken as an example because of the impact the IT system has on it. We will see later in this research. Many countries in the developed world use the IT system in the sector but we will note the difference in that our information technology system is still basic compared to those countries. The IT system is one of the most important ecosystems in the world [1]. Because of advances in the use of information technology in recent years and the increasing sophistication in all areas of life, this service has made it possible for many people to communicate directly with one another and search in global libraries, scientific journals, websites, and other important features, the basic benefit of this system is to improve the quality of health care [2].

This study shows the nature of the relationship that exists between independent and dependent variables. To determine the relationship between the variables, person correlation was run between the variables, a perfect positive correlation was found between two variables, which is represented by 1.0 (plus 1), or a perfect negative correlation which would -1.0 (Minus 1) as shown in Figure 2. Whereas, the correlation might range between -1.0 and +1.0 , the researcher conducted this study to know if any correlation found between two variables is significant or not (i.e., if it has occurred solely by chance or if there is a high probability of its actual existence). As for the information, a significance of $\mathrm{p}=$ 0.05 is the generally accepted conventional level in social sciences research.

Due to the increase in the population, there is a need to improve the quality of health services provided so that they become affordable for all because of their impact on human health. An example of these methods used in improving health care is the "efficiency of health workers" [2].

One of the most important issues that the health care sector focuses on is improving the quality of treatment and patient satisfaction with this service. The IT system in this field may be improved by other issues such as efficiency in performance through the availability of this service and its facilitation in the field of health care [3]. "In the past years we have noticed a rapid and growing evolution of the IT system in all sectors, thus making it difficult to produce health services" [4]. 


\section{Problem Statement}

At the beginning of this study and after the survey among the employees of Yemeni hospitals in the capital Sana'a, the researcher noted that the information use of the IT system is insufficient among the staff. The researcher concluded that previous studies in this field might be almost non-existent. In this research, we notice the role of the IT system and its impact on the health care sector directly. Due to the emergence of the above problem, there is a need to search for the tools of the technology used as shown in the literature, which may help improve the IT system in Yemeni hospitals.

In addition to the need to search for scientific evidence by evaluating the tools of the information technology, system and its impact on health care so as to stimulate hospitals to use them in the correct ways. The problem of study from the point of view of the researcher in the knowledge is that there is an impact of the use of the information technology system in the hospitals in the capital Sanaa on the quality of services of these hospitals.

\section{Literature Review}

The public sector contains many basic and important elements, in which the most important component is health care [5]. "Health care is one of the most important challenges and difficulties facing most of the world especially developing countries [6]. One of the most important challenges that the health care sector may face lately is how to cooperate and coordinate effectively through geographical, institutional and professional boundaries [7]. Many benefits can be achieved and some points of health care are addressed to all individuals including improved access to care by patients and improved quality of medication [3].

\section{Healthcare System}

Healthcare systems can be defined as the institutions that supply health care treatments including equipment, residential care accompanied by other services for treating the patient. Recently there are so many different options for health care systems that the choice can often be very difficult [8]. WHO [9]" in a broad term defines the health system as "A health system involves of all organizations, people and programs whose primary determined is to promote, rebuild or keep health safe". A rapid and significant change was observed in the health care sector where the situation became worse and chronic health problems worsened over time [10]. The medical system is a specialized system that includes a number of specialized personnel in different fields, through which they facilitate medical services and provide the necessary health care. It is not without complications that accompany this system [11]. The health care system is one of the most complex systems [5], Health care systems are considered one of the most complex systems through coordination between the hospital and outside hospitals, which work hard to provide the appropriate service to the patient [3].

\section{IT Adoption in Health Sector}

Recently many countries of the world have introduced an IT system into 
health care systems and have become the most dependent system in this field [12]. The information technology system in the medical sector is used very remarkably; the information technology system is adopted significantly in the health sectors [13]. Now, many hospitals are using an IT system that helps medical professionals and facilitate their work [14].

Health care providers provide support in the field of information technology on health systems despite the challenges that exist in the world [14]. The healthcare system depends on the extraordinary use of information technology in all countries of the world, such as the adoption of the electronic registration system and the Internet system and others [15]. There are many developed countries in the world that have invested huge amounts of money to help adopt an electronic health care system [16].

The reasons for the increased adoption of the IT system in the health sector

Using the information technology system is a main shift in the health sector and is expected to become most widely used systems in the next few years [6] [17], In addition, this system will provide many facilities and most importantly the active role of the patient in the field of health care [14]. Viitanen [14] the researcher believes that familiarity with the use of the health technology system will play an important role in improving the health care provided by facilitating the role of workers and reducing the pressure on them. However, we should know that there are several factors that directly effect on the adoption of the IT system in the field of health care. The researcher found the following factors:-The first factor, As a result of the rapid development of information technology, this has led to the adoption of technology in most sectors of government and the most important sectors of health and this may cause a significant change in the quality of health care [18]. The second factor is to reduce the budget of certain equipment used as sensors and screens [19].

The third one is the rapid and growing development of the use of Internet networks and network information systems to give new opportunities to share health information effectively and quickly through telecommunications systems [19]. The fourth factor, Patients will be treated directly, especially in personal health care [10]. The fifth factor allows the use of wireless communication devices and access to all information systems at any time and gives amazing opportunities to get some valuable feedback through feedback to improve the quality of health care and patient satisfaction [20]. In order to improve self-patient management there are new opportunities for the patient to receive appropriate advice via the use of feedback [10]. The sixth factor, recently, the information technology system in the health care sector has become a target for all users for all purposes because it contains a wide range of services and applications [14]. Seven factors, as the use of the computer system in all sectors of the state increases, the IT system can occupy an important place in health care sectors [21]. Finally, many benefits may be obtained from ICT in healthcare, as we will see 
later in this research.

\section{Challenges Facing Healthcare area with Adoption and Usage of ICT}

There are many difficulties that we may face in dealing with all the different fields and focusing on using information technology in health care. The researcher will identify briefly what he found in a number of prior literature.

Many countries around the world are seeking to adopt the technology system in health care sectors but face many difficulties that must be resolved before applying it [16]. So the implementation looks like so difficult” [22].

Fortin et al. [23] the researcher pointed out that the most important reasons for the lack of adoption of information technology is unsatisfactory assessments so far, and the main obstacle to the application of this system in the health sector that the effectiveness and existence of this system is very weak.

Viitanen [14] in the same context pointed out that the biggest problem facing the use of technology is the lack of training on devices, which is an important part of the work and stressed the importance of training and rehabilitation in this aspect.

Marrow [17] too agreed that training is the most important part of the use of information technology. He said that the more training, the more effective the results and the main reason for the successful implementation of this system in the field of health care. Gagnon [23] when mentioning health care comes to mind the medical staff in general and patients in particular, so the researcher believes that the most important difficulties are the participation of the patient in the use of technology in a certain way and here prefer to give patients appropriate training opportunities. In the computer health information system, limited training is one of the most important uses of information gathered until now [24].

In the past, there have been many obstacles to health care where the patient is considered the biggest challenge and that is by engaging in a particular technique so he has to get the proper training to use this technique [6]. Clemensen et al. [6] deduced some of the challenges that appear when using a video connection technique to be:

1) The difficulty of direct contact.

2) Lack of knowledge of the technology leading to the reluctance to use selfcare.

3) The quality of video usage is unclear due to a poor internet connection.

4) Lack of some skills such as motor skills and knowledge.

Returning to Viitanen [14], the difficulties faced by the public whether developed or developing when using the IT system in the health care sector are as follows:

1) Demonstration of complex medical data.

2) Some problems in the process of inserting and outputting data.

3) Security Complexities.

4) There is no clear identity for the patient. 
5) Insufficient awareness of the benefits and risk of this technical information.

Omary et al. [16] found out that some of the challenges faced by developed and developing countries using the IT system in the health care sector are as follows:

1) lack of clear identity for the patient.

2) Poverty and lack of Internet availability, which is significant.

3) Lack of health care policy in the medical sectors.

4) Lacks international standards.

5) The existence of security complications.

The main problem in the use of the IT system in developing countries was simple and possible in developing countries, but because of the different circumstances and factors of the developed countries where most of the tests and implementation come from [25], the main problem in the use of the IT system in developing countries was the lack of funding, although the implementation of such systems is simple and possible in developing countries, but because of the different circumstances and factors of the developed countries where most of the tests and implementation come from [24], implementation becomes a problem.

\section{Impact of Information Technology system on health care}

\section{- Information Technology in General}

Scientific and industrial achievements are still in rapid development and the renaissance in the use of the IT system is one of the most important achievements recently [18].

Literature shows that "rapid progress in the IT system, which has caused problems in the health care sector" [4]. The researcher mentions that there are several benefits of using IT systems in our daily lives [16].

The information technology system in the health sector is being used increasingly [26]. It has great importance in improving the quality of care and in caring for patients [14]. Information work is the main and important item in the health care sector [27], Hence we note its importance as a dense industry for the use of information [5] [13] [16]. When a patient visits a health care center, it is based on a digital or paper version containing health information about the patient (patient health information PHI) [16]. This is considered one of the most important difficulties facing the general medical staff and the private doctor in wasting time by collecting data [27]. In addition to this, the nurse should play a large role by providing consultation or cooperation with doctors in all specialties [10]. In case of need of doctors or nurses for some health, information should be available at anytime and anywhere and clearly [3].

From here, we can define HIS as a specialized system for managing tasks in the health care sector [16]. There was an impact on clinical work in hospitals through the adoption of an IT system [14], It is also important for the computerized system and data collected in the Department of Patient Care Management [20].

One of the most important systems that rely on documents and papers (HIS) is an electronic system that has various functions and uses [24]. It may contain 
one or more specialized computer programs as well as various sub-systems such as a laboratory information system [16]. Clear coordination of data is one of the most important factors in this area [3]. The health system calendar depends on the appropriate health information and correct information systems [24], this shows perfectly in improving quality and minimizing medical errors [16], it also has a role in distributed resources by supporting real coordination [20].

\section{Information Technology Background}

The use of modern means of communication such as the smartphone and the Internet has become more widespread in the last few days [10].

The use of infrastructure for information technology is very important so that information is shared in the health sector as well as other sectors [17]. Hence we note the interest of rich countries in the development and investment of telecommunications infrastructure in all systems, especially the system of health care provision [14].

All health sector staff, whether administrative or clinical, must diversify the collection of patient information and adopt different sources for this purpose [17].

Communication must be maintained between all hospital departments and all related departments [17]. Health care services are widely distributed, but there is a notable presence for many specialists in all specialties [3], this indicates the importance of sharing and sharing information among health and patient workers [28].

The characteristics of the network in the health sector are taken advantage of through co-operation and collaboration among the working personnel [17].

One of the most important ways to improve health care is to connect health facilities, network communications, and information technology [29].

There is also an important way to improve the health of citizens and manage their patients through continuous interaction between service providers and patients [14].

The provision of health care services depends on the cooperation of the shareholders in this service through organizational boundaries [28]. Also, "Through experience and studies proved that patients who consult a health sector resort to treatment and stay in another health hospital for different reasons" [29]. Until a proper diagnosis is obtained and given effective medication there is a need for coordination and good communication between work activities in all health care sectors [3].

The importance of coordination processes directly or through the electronic system It helps in the diagnosis and access to information and data and facilitate processing and conservation and thus the participation of beneficiaries of the service [11]. Nicola \& Jarke [29], the distributed information system should be considered as an important and useful system for diagnosing general diseases and assessing the health status of the patient.

Tools are using in Healthcare

Many tools are used in the health care sector and this may be done directly or 
indirectly, as many depend on them, such as using the Internet, for example using the e-mail tool.

In addition, there are direct ways to benefit from this care by means of direct communication such as mobile phone use. We can point out that no matter how different the tools are but give the same effect, in this part we will discuss the tools that affect the use of the IT system in the sector Health care and focus on the importance of these tools and we can summarize as follows:

Internet, Electronic Mail (E-Mail), Health Web Portals, Electronic Health Records (EHR). Telemedicine or Telehealth, Mobile Health (M-health), and Mobile Phone.

\section{- Internet}

Health sectors in the future will depend on technology, especially the computer and the Internet [10]. With the era of technology and the Internet and rapid development in recent times, this has led to the development of the concept of management in a modern manner [4].

Because of its importance in helping the doctor to retrieve information at any time, the Internet has become important for both doctors and patients [16].

With the widespread and continuous use of the Internet and the increasing use and utilization of the Internet in all areas has become an important source in the health care sector and it has become possible to obtain the necessary medical information [18]. Where information in all fields, especially in the medical field, has become accessible to everyone [15]. There are many websites that may reach 100,000 sites worldwide and each site contains a variety of health information that may benefit consumers or beneficiaries [30]; There are also many Internet users around the world using the Internet to search and choose the best and most appropriate health information [31].

We note that due to the rapid development of technology usage many service providers rely heavily on the use of the Internet [30].

On the other hand, the benefit of self-service management is one of the most important features of the Internet tool [10]. This gives an area for the patient to search and surf the Internet and identify many medical and therapeutic conditions [15], But this does not apply to all patients [10], because the use of the Internet is linked to the impact of factors (age, sex, education, etc.) [32].

\section{- Electronic Mail (E-Mail)}

E-mail is one of the most important tools used and has several functions and this tool is suitable for many cases such as non-emerging cases because it facilitates the consumer to save the electronic record and data and take it out when necessary [33].

Recently, there has been a noticeable increase in the use of e-mail in the health sector [32], and works to strengthen the relationship between the patient and the doctor and between doctors working in the same specialty or in other areas [18]. It uses the most important purposes of managing appointments and providing test results [32]. It uses the most important purposes of managing appointments and providing test results [6]. 
One of the important things that may facilitate the patient who has the ability to use the Internet is to inquire about any examination or any health problem with email and receive the answer from the doctor [30]. Here we note that the provision of email has special importance in engaging patients in the health care sector [32].

Often there is not enough time by the doctor for the patient but the time is very limited so the use of e-mail service facilitated this problem [31]. Therefore many patients notice the important consultation of a physician by using email [33].

As the information that arrives from the doctor through the website has more benefits than other methods because it may explain the case in detail, so the patient can keep it and considered a reference can refer to when necessary [32].

\section{- Health Web Portals}

Active server pages (ASP) are one of the most active pages on websites and have a number of followers who use them to know their answers. Through this program, they can analyze the patient's data and give him the advice to go to the doctor [33].

It is considered one of the most important means of electronic communication because it is easy to communicate with audio and video [18].

One of the most important methods of adopting e-health that improves the quality of health care for patients is the healthy web portals [16]. It is considered one of the most important Internet tools used in the field of electronic health records, thus it facilitates the transfer of patient data at home to the doctor or to health professionals [34].

Due to some population, variables such as population increase policies are being taken that lead to reduced reliance on health care in the hospital

[17], thus the patient becomes involved in this care as he plays an important role in making your health care decision [31].

Sometimes web services may be used by self-diagnosis Of the patient in particular cases and this, in turn, leads to determine whether the patient needs to be consulted by a clinical specialist or not [17].

In addition to the above, the presence of such services facilitates both the patient and the doctor as the patient may recognize the type of healthy life and self-treatment, read, and benefit from them, and that the doctor uses these sites in the search for medical information and participation [16].

Note that the importance of web pages is to give general information about the patient as some of the health problems faced by the patient and thus enable him to search for information linked at any time he wants, and an example of these health problems (quit smoking, causes of obesity,) [32].

- Electronic Health or Medical Records (EHR, EMR)-General Overview

Health records are one of the most important tools in the hospital information system. They facilitate access to medical information and read health records. It also allows users to easily search for and access information [26]. 
There are many terms that are traded in electronic records, such as computer-based patient records (CPR), computerized medical records (CMR), patient-carried medical records (PMR) electronic patient records (EPR), electronic medical records (EMR), personal health records (PHR) and digital medical record (DMR) [16].

The collection of health information about paperwork is different from electronic health care, so that by using the files and folders, the collection of information becomes difficult, as information is collected for the patient at each visit. Otherwise, the health information is collected once and returned to it at any time. [16].

We note that health sector workers suffer greatly from the collection of information and records of patients who rely on papers and vice versa in the use of electronic records, as it facilitates the patient's participation in the information and thus improves the quality of health care [28].

The process of using electronic records through the transfer of paper to electronic data containing inside the details and details of patients, in addition to the doctor's observations and medicines and analysis necessary [34].

Patients' records are treated by the hospital staff as a store that contains all the basic and necessary information in all types of primary, secondary and tertiary care, where it is used for the purposes of the most important of which is to facilitate patient service, data preservation and evaluation of its results, [14].

Theoretically, with the use of the e-care system, it is much easier for patients to obtain patient data at any time. Similarly, the doctor has benefited from this service, where he is able to receive many patients, unlike a doctor who works in the framework of health care [16].

A long time ago, the process of collecting patient data from the clinic was somewhat difficult, as the nurse had to look for the patient's data between the papers and documents such as the use of fax or by telephone so the use of electronic records facilitated their work by accessing the required data at any time [22].

A number of outpatient primary care clinics have adopted the use of an electronic health record system in their practices [35].

Recently in the most developed countries, the electronic health record is adopted significantly [14]. It is adopted as an important application in the field of health care by providing electronic patient records and these are considered as the most important electronic health care services [16].

Many developed countries support the electronic registry system as well as national health records and through huge investments in this field [14].

\section{- Telehealth or Telemedicine}

Telemedicine is defined as the use of the IT system to provide remote health services [33]. This is done when the patient is in a distant place and the doctor is in another place meaning that they are not in the same environment [16].

There are two types of telemedicine either simple or complex, the simple is by phone, which is used to solve a problem, and either the complex through which 
the satellites are used [16].

One of the main reasons for the emergence of this type of tool is the rapid development in technology has helped the emergence of many who cannot receive health care directly in the special centers [33].

It was previously difficult to allow the patient to participate in the doctor's self-monitoring of his health but after the use of telemedicine, which enabled many patients to educate and follow up their disease remotely and thus facilitate the health care of a large number of individuals [6].

As for the eternal health of the concurrent be through a visual connection using the phone and a dialogue between the doctor and the patient and discuss the health situation and here is delegated patient participation in the case, As for the secondary non-synchronous health comes the importance of non-transfer of data at regular intervals, which leads to the possibility of changing the results since the sender and the future should not be synchronized length of time, for example, when following a specific disease such as liver disease, the patient can access his data and follow-up treatment progress and this gives him Psychological condition is good [6].

- M-Health

Kahn et al. [15] we can define mobile health as direct use of electronic devices through voice communication and the transfer of necessary data from the centers dedicated to health care.

Recently, the use of this type of technology has increased because of the rapid development of information technology [14]. WHO implemented a survey to its member states and the survey found that most member states use M-Health initiatives: $83 \%$ of the 112 participating member states reported the presence of at least one M-Health initiative in the country [36].

In many hospitals, mobile phone usage is widely observed and with the increasing sophistication of information technology, this will lead to the adoption of mobile phone usage in the future [17].

Due to the rapid development of the health sector, wireless infrastructure has become a major and prominent role in most mobile communities [14].

\section{- Mobile Phones}

The phone is one of the most used technology in the world compared to other tools [15].

Doctors were treating their patients by phone and still recommending it [33].

With the technological advancements of the mobile phone, this has made it possible for both the doctor and the patient to communicate rather than to meet directly or communicate by speaking. This is easy to service the patient's health care [10].

Because of the increasing sophistication of technology and its availability to consumers, the use of mobile phones has become important in providing health care services [14].

The concept of health care is changed from one period to the next but it is ex- 
pected that the health advice will be via mobile phone, most notably [10].

\section{Methodology of the Study}

The purpose of this study was to find out the impact of using the IT system in the hospitals of Yemen and how it can improve the health care process from the point of view of the health workers in hospitals. To achieve this goal, the researcher followed the analytical descriptive method using the applied method, including the use of a number of statistical methods and treatments related to the study of the subject, without intervention by the researcher Thus, the researcher can interact with these situations, analyze, and describe them.

The current study is an applied study based on descriptive analytical methodology using a questionnaire prepared by the researcher to be a tool to obtain the information needed by the applied side of the study and based on the available literature and related studies.

The study concludes a basic type of data, which is the primary data obtained from a systematic questionnaire distributed among health workers in Yemeni hospitals where the researcher tried to describe and analyze their views. After the distribution of the questionnaire and the collection of data, a statistical analysis was carried out in order to obtain the final report and the necessary results through a statistical program called SPSS.

\subsection{Research Data}

Primary data was used in this study and the researcher used questionnaire and distributed it to the health workers in Yemeni hospitals. Data collected were analyzed by SPSS and described from the point of view of health workers. The researcher suggest his hypothesis according to the variables that present in the study as shown under Figure 1.

\subsection{Data Collection}

The questionnaire was distributed to the health workers in Yemeni hospitals.

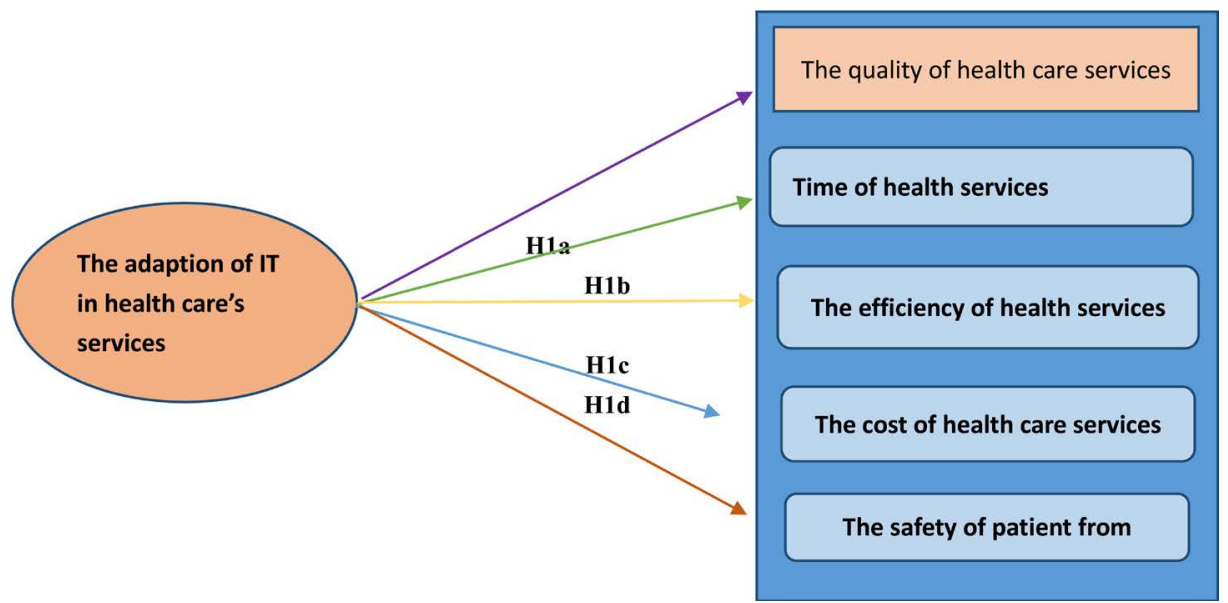

Figure 1. Study model. 
The distribution was random at first but the researcher noticed the response rate was rather low due to difficulty in collecting data from doctors and related staff. The researcher changed his work plan and did intensive work to obtain an acceptable number of questionnaires. The number of the questionnaire responses was about 430 copies, 23 copies were canceled because they were not valid and the remaining 407 copies of the questionnaire responses were valid and available for analysis. The researcher considered this number of questionnaires sufficient to complete the research study.

\subsection{Research Population}

The research population was the Yemeni employees in the hospitals of the capital Sana'a. According to the reports of the Yemeni Health Ministry in 2016, the number of health workers both in the public and the private sectors is about 4428 employees.

\subsection{Research Sample}

The study targeted workers whose nature of work was clinical, nursing, or paramedical. The sample size used in the research was the 407 respondents which is more than the acceptable size of 378 . To determine the reliability and validity of the data collected, the credibility of the responses and the questionnaire was tested using Alpha Kronbach to ascertain the stability of the questionnaire and the credibility of the sample.

\subsection{Research Tool}

Depending on what found in the literature, the questionnaire was designed to collect the initial data then analyze it for the purpose of the research. The questionnaire was designed in two copies (Arabic and English) and distributed in the Arabic version to the participants as the Arabic language is their mother tongue.

\subsection{Analysis of Data}

The data obtained were analyzed using SPSS and presented in form of tables. Descriptive statistics such as frequencies, percentages, means, standard deviations, and Pearson product-moment correlation coefficient used to analyze the data.

\subsection{Research Hypotheses}

The study aims to test the following hypotheses:

Hypothesis (1): we have evidence that the high adaption of IT (information technology) is supported by the quality of health care services.

Hypothesis (1a): we have evidence that the high adaption IT (information technology) is supported by the time of health care services.

Hypothesis (1b): we have evidence that the high adaption IT (information technology) is supported by the efficiency of health care services.

Hypothesis (1c): we have evidence that the high adaption of IT (information technology) is supported by the cost of health care services. 
Hypothesis (1d): we have evidence that the high adaption of IT (information technology) is supported by the safety of patient from medical errors.

\section{Results Analysis and Discussion}

This chapter will explore the descriptive statistical analysis of the data obtained from the questionnaire distributed to the sample respondents, Present research analysis and discussions, and examine the hypothesis of the study and its statistical significance.

\subsection{Demographic and Descriptive Analysis}

The questionnaire was distributed to a number of Yemeni hospitals in the capital Sana'a consisting of eight public hospitals and three private hospitals as shown in Table 1 below:

The first part of the questionnaire is the demographic variables, which contain personal information related to the respondents. Furthermore, this information is different between the respondents in the research sample. The following discussion analyzes the first part of the questionnaire to describe the demographic distributions of the respondents and to show the differences between them.

The respondents in the research sample were divided into two genders (male and female). As shown in Table 2, the number of male respondents was 206, and the female was 201 . The percentage of two genders was approximately the same. The age variable in the questionnaire was divided into four sections as shown in the following above, the number of $30-20$ year's respondents was the highest with a percentage of 346 , and the proportion gradually decreases from even younger age groups. 31 - 40 years was 35 , after that the category $41-50$ years was 21 , finally, more than 51 years was 5 respondents, this means that there was the lowest proportion among respondents of the older age groups. To interpret the result we can think of three options, first, the health sector had a great development in the past few years, which led to the recruitment of many young cadres where the Yemeni Ministry of Health reports that the size of the workforce in the health sector has increased significantly over the past few years.

Table 1. Name of hospitals.

\begin{tabular}{cccc}
\hline Name of hospitals & Types & Frequency & Percentage \\
\hline Ibn sina & Private & 17 & 4.2 \\
Azal & Private & 86 & 21.1 \\
Al-Thawra & Public & 51 & 12.5 \\
Al-Jomhwri & Public & 36 & 8.8 \\
Al-Sabeen & Public & 23 & 5.7 \\
Police & Public & 48 & 11.8 \\
Science \& Technology & Private & 97 & 23.8 \\
Al-Kuwait & Public & 49 & 12.0 \\
\hline
\end{tabular}


Table 2. Statics of demographics variables.

\begin{tabular}{|c|c|c|c|}
\hline Attribute & Distribution & Frequency & Percentage \\
\hline \multirow[t]{2}{*}{ Sex } & Male & 206 & 50.6 \\
\hline & Female & 201 & 49.4 \\
\hline \multirow[t]{4}{*}{ Age } & $30-20$ years & 346 & 85.0 \\
\hline & 31 - 40 years & 35 & 8.6 \\
\hline & $41-50$ years & 21 & 5.2 \\
\hline & More than 51 years & 5 & 1.2 \\
\hline \multirow[t]{5}{*}{ Qualification } & Diploma & 119 & 29.2 \\
\hline & Bachelor & 228 & 56.0 \\
\hline & Master & 23 & 5.7 \\
\hline & Higher & 17 & 4.2 \\
\hline & Other & 16 & 3.9 \\
\hline \multirow[t]{2}{*}{ Type of hospitals } & Public & 207 & 50.9 \\
\hline & private & 200 & 49.1 \\
\hline \multirow[t]{3}{*}{ Type of jobs } & Doctors & 120 & 29.5 \\
\hline & Nurse & 152 & 37.3 \\
\hline & Help jobs & 126 & 32.7 \\
\hline \multirow[t]{5}{*}{ Experience } & Less than 1 year & 80 & 19.7 \\
\hline & $2-5$ years & 180 & 44.2 \\
\hline & $6-10$ years & 73 & 17.9 \\
\hline & $11-15$ years & 43 & 10.6 \\
\hline & More than 16 years & 30 & 7.4 \\
\hline \multirow[t]{2}{*}{ Supervision degree } & Yes & 62 & 15.2 \\
\hline & No & 337 & 82.7 \\
\hline \multirow[t]{4}{*}{ Impact of IT on health care } & Positively affects & 323 & 79.4 \\
\hline & Negatively affects & 8 & 2.0 \\
\hline & Does not affects & 28 & 6.9 \\
\hline & I don't know & 31 & 7.6 \\
\hline
\end{tabular}

Second, for older employees either to be promoted to senior positions to benefit from their experience or to be seated and to give new opportunities to new employees. Finally, because of the current situation in Yemen, some have been forced to leave to safer places, which in turn has led to the availability of many vacancies and allowed new job opportunities.

The qualification variable in this part shows the results of the study were divided into five levels (diploma, bachelor, master, higher, other). From above we can observe the distribution details in the educational levels between the sample of the research where the highest educational rate was bachelor degree with 228 after that diploma was 119, then Master degree 23, Higher with 17 respondents, and finally others with 16 respondents, with 4 respondents missing values. We cannot find any studies or statistics related to this distribution, but the research- 
er believes that this distribution is due to the reality of education in Yemen, especially the crisis experienced by Yemen since 2011-2018.

Two types of hospitals were used in research (government, private). Table 2 shows the distribution data in each hospital. We note that the percentage of government hospitals and private hospitals is relatively close to each other. The number of governmental hospitals was 207 respondents and the private hospital was 200 respondents. It can be explained by the result that hospitals in the private sector in Yemen are an important factor for almost half the human cadres. This may be due to the researcher's view that the private sector is constantly developing because of its excellent services, which in turn attract a large number of patients, and this is of great financial benefit to the hospital thus increasing employment.

The type of work targeted three categories of respondents by nature as shown in the table. The number of Nurses was 152 and it was the highest percentage among the respondents, we can explain that the work of the nurse requires permanent presence in the workplace and this is what appeared in the results of the search where the highest proportion among respondent 37.3, because of easy access to them unlike doctors and their absence in the workplace, making them the lowest rate, doctor was 120 , and help jobs was 126 respondents. A missing value was nine respondents.

The period of experience for respondents was divided into five periods as shown in the following Table 2, the number of respondents with 2-5 years' experience was 180 , after that less than one year was 80 , and 6-10 years was 73 , and 43 years for category of 11-15 years finally more than 16 years 30 respondents. One respondent was the missing value. We note from the table that the percentages of respondents who have years of experience more are the lowest proportion when compared to the rest of the experience either respondent who has little experience periods are the largest proportion. When we compare the experience result with the results of the age variable in the table number 2, we note that the result is logical because the youth are the highest. Table 2 shows the supervisory level for each of the sample of the research and shows those who do not have any supervision degrees. It is noted that the result was logical, where the percentage of respondents who have a degree of supervision about $15.2 \%$, which is about one third of the respondents and this, is logical for the number of samples found, and who haven't degree in supervision was $82.7 \%$ and 2.0 respondents as a missing values.

As shown in the above Table 2, the number of respondents of how the information technology system affect positively the healthcare was 323 , and I do not know was 31 respondents, Does not affect was 28 respondents, and finally negatively affects with 8 respondents. The missing value was 17 respondents.

When explaining this point we note that the highest percentage of those who believe that the use of the IT system has positive effects and these positive effects, as they say, lies in that some patients when visiting a hospital in order to treat certain health problems, the patient should do all the Routine medical transac- 
tions that he has done every time. This, in turn, is difficult to work on the employee and also on the doctor because of the lack of a satisfactory history of the patient who may help the doctor to diagnose the situation better. And this, in turn, leads to the loss of some important information that helps in diagnosis; in addition, it becomes more expensive for the patient in each visit. This indicates that a high proportion of respondents aspire to the availability of the information technology system in the health care sector because of its positive effects to improve the health care services provided. This is shown in the table where the lowest percentage of respondents who expect the negative effects of using the information technology system.

\subsection{Descriptive Statistics}

Descriptive analysis includes the mean and the standard deviation for the dependent and independent variables explained in the following sub-sections;

Table 3 shows that paragraph 3 got the first rank with a mean of 3.79, and standard deviation of 1.44 . The highest percentage $75.84 \%$ of respondents agrees. The hospitals have a system enable lab results to be entered and returned electronically Paragraph 4 ranked last with a mean of 3.15 and a standard deviation of 1.48. The overall average of the variable is 3.56 and the standard deviation is 1.31 with the degree of confidence at $71.33 \%$.

\section{Hypothesis:}

We have evidence that the high adaption of information technology is supported by the quality of health care services.

Result:

There is a supported impact when applying the IT system to health care services.

\section{Descriptive Statistics of the main four variables:}

In the third part of the questionnaire, the impact of the information technology system on health care is explained and divided into four dependent variables (time, effort, cost, and safety). Each section below contains five paragraphs related to it. It has been formulated to be answered by the respondents from the same sample. Each paragraph analyzed and discussed as the following:

Table 3. Descriptive Statistics of Adoption level of information technology system IT SYSTEM Effects.

\begin{tabular}{|c|c|c|c|c|c|}
\hline Rank & Question number & Mean & $\begin{array}{l}\text { Standard } \\
\text { deviation }\end{array}$ & Average rate & $\begin{array}{l}\text { Verbal } \\
\text { appreciation }\end{array}$ \\
\hline 2 & 1) The hospitals have a system to register and acquire patients data & 3.789 & 1.435 & $75.78 \%$ & Agree \\
\hline 3 & 2) The hospitals have a system to set medical orders and lab requests & 3.724 & 1.436 & $74.47 \%$ & Agree \\
\hline 1 & $\begin{array}{l}\text { 3) The hospitals have a system enable lab results to be entered and returned } \\
\text { electronically }\end{array}$ & 3.792 & 1.441 & $75.84 \%$ & Agree \\
\hline 5 & 4) The hospitals have an electronic reminder system & 3.159 & 1.484 & $63.18 \%$ & Natural \\
\hline \multirow[t]{2}{*}{4} & 5) The hospitals have a system used in the diagnosis and in giving medications & 3.337 & 1.482 & $66.74 \%$ & Neutral \\
\hline & Average variables & 3.566 & 1.317 & $71.3 \%$ & Agree \\
\hline
\end{tabular}




\section{First variable time:}

Table 4 shows the analysis of methods and standard deviations and the degree of approval for each of the paragraphs in the third part of the questionnaire. The time is the first part of the variables. Through this analysis, we can see the respondents' view in the same eye the impact of the information technology system on the health care sector through save time in the service provided in Yemeni hospitals. As the table shows that paragraph, one got the first rank with a mean of 4.56 , and a standard deviation of 0.75 . The highest percentage $91.26 \%$ of respondents highly agrees. It is systematically followed by paragraphs 2, 3, 4 and the lowest Paragraph 5 ranked last with a mean of 4.03 and a standard deviation of 1.07. The overall average of the variable is 4.394 and the standard deviation is 0.704 with the degree of confidence at $87.87 \%$.

\section{Hypothesis:}

The time variable was chosen to test the statistical hypothesis that said (we have to evidence that; the high adaption of IT (information technology) is supported with the time of health care services).

As indicated above, the time zone has been approved to a high degree average of 4.56 , which is larger than the neutral degree $2.59-3.39$.

\section{Result:}

The hypothesis was accepted, that there is an impact by using the IT system on health care and it gets better whenever there is saving time (Table 5).

Table 4. Descriptive statistics of time.

\begin{tabular}{lcccc}
\hline \multicolumn{1}{c}{ Question number } & Mean & $\begin{array}{c}\text { Std. } \\
\text { Deviation }\end{array}$ & Rank & $\begin{array}{c}\text { Approval } \\
\text { Degree }\end{array}$ \\
\hline $\begin{array}{l}\text { 1) Speed up data exchange and transfer between } \\
\text { departments }\end{array}$ & 4.563 & 0.752 & 1 & Highly agree \\
$\begin{array}{l}\text { 2) Speed up medical orders process } \\
\text { 3) speed up patient information acquiring }\end{array}$ & 4.475 & 0.780 & 3 & Highly agree \\
$\begin{array}{l}\text { 4) Speed up access and return to medical records } \\
\text { 5) Physicians can dedicate more time to patients }\end{array}$ & 4.394 & 0.837 & 4 & Highly Agree \\
\multicolumn{1}{c}{ Average variable } & 4.036 & 0.808 & 2 & Highly Agree \\
& 4.394 & 0.704 & 5 & agree \\
\hline
\end{tabular}

Table 5. Descriptive statistics of effort.

\begin{tabular}{lccccc}
\hline \multicolumn{1}{c}{ Question number } & Mean & $\begin{array}{c}\text { Std. } \\
\text { Deviation }\end{array}$ & Rank & $\begin{array}{c}\text { Approval } \\
\text { Degree }\end{array}$ \\
\hline $\begin{array}{l}\text { 1) Easy communication and coordination between } \\
\text { departments }\end{array}$ & 4.484 & 0.777 & 2 & Highly agree \\
$\begin{array}{l}\text { 2) Easy medical orders requests } \\
\text { 3) Easy up access and return to medical records }\end{array}$ & 4.466 & 0.774 & 5 & Highly agree \\
$\begin{array}{l}\text { 4) Helps in surveys and medical research } \\
\text { 5) Helps in preparing reports and statistics }\end{array}$ & 4.344 & 0.712 & 1 & Highly agree \\
$\quad$ Average variable & 4.472 & 0.909 & 3 & Highly agree \\
& 4.461 & 0.707 & 4 & Highly agree \\
& & & & Highly agree \\
\hline
\end{tabular}




\section{Second Variable: Effort}

Table 6 shows analysis of methods and standard deviations and the degree of approval of each of the paragraphs in the third part of the questionnaire and the effort is the second part of the hypotheses. Through this analysis, we can see the respondents' view in the same research towards the impact of the system and information technology to the health care sector by providing the effort in Yemeni hospitals as Table 6 shows that paragraph 3 got the first rank with a mean of 4.54, and standard deviation of 0.712. The highest percentage of $90.89 \%$ of respondents highly agrees in paragraph 3 . Sequentially followed by paragraphs 1, 4, 5, where Paragraph 2 was the lowest of the paragraphs ranked last with a mean of 4.46 and a standard deviation of 0.77 . The overall average of the variable is 4.46 and the standard deviation is 0.707 with the degree of confidence at $89.22 \%$.

\section{Hypothesis:}

The effort section was selected to test the second hypothesis, which said (we have evidence that, the high adaption of IT (information technology) is supported with the effort of health care services).

As indicated above, the effort section has been approved at a high rate of 4.54, which is greater than neutrality that informs $2.59-3.39$.

\section{Result:}

The hypothesis was accepted, that there was an impact by using the IT system on health care and it was improving through the effort

\section{Third Variable: Cost}

Table 6 shows the standard methods and the degree of approval for each of the paragraphs in the third part of the questionnaire. The cost variable is in the third section of the hypotheses. Through this analysis we can note the respondents' view in the same research regarding the impact of the IT system on health care and that by providing cost in the right hospitals. The Table shows that paragraph 2 got the first rank with a mean of 4.33 and a standard deviation of 0.908 . The highest percentage of $86.70 \%$ of respondents highly agrees in paragraph 2 . It is sequentially followed by paragraphs $1,4,5$. Paragraph 3, ranked last with a mean of 3.82 and a standard deviation of 1.09. The overall average of the variable is 4.05 and the standard deviation is 0.764 with the degree of confidence at $81.13 \%$.

Table 6 shows that the degrees in 3, 4, 5 were moderate. This means that the

Table 6. Descriptive statistics of cost.

\begin{tabular}{ccccc}
\hline Question number & Mean & Std. Deviation & Rank & Approval Degree \\
\hline 1) Reduce medical tests redundancy & 4.318 & 0.874 & 2 & Highly agree \\
2) Reduce paper usage & 4.335 & 0.908 & 1 & Highly agree \\
3) Reduce the patient length of stay & 3.827 & 1.090 & 5 & Agree \\
4) Reduce average of patient visits & 3.712 & 1.081 & 4 & Agree \\
5) Reduce medical errors & 4.102 & 1.024 & 3 & Agree \\
Average variable & 4.057 & 0.764 & & Agree \\
\hline
\end{tabular}


respondents' expectations are in a moderate range and were not achieved if there is an impact on the cost of health care. This may be due to the pressure of work and its difficulty in relation to the workers and this makes them tend to end the exhaust at night rather than getting sick in the daytime.

\section{Hypothesis:}

The cost section was tested for a third hypothesis test that said (we have evidence that the high adaption of IT (information technology) is supported with the cost of health care services)

As explained above, it was approved at a high cost of an average of 4.33, which is greater than the degree of neutrality, which reaches $2.59-3.39$.

\section{Result:}

The hypothesis was accepted and it was agreed that there was an impact by using the IT system on health care and that it was improved by providing cost.

\section{Fourth variable: Safety}

Table 7 shows the analysis of the standard methods and the degree of approval for each of the paragraphs in the third part of the questionnaire and was in the fourth part of the hypotheses. Through this analysis, we can observe the respondents' view of the same research regarding the effect of the IT system on health care by maintaining patient safety in Yemeni hospitals. The research identified a high degree of approval that the IT system maintains the patient safety in the right hospitals and shows that the highest degree of answers was in paragraph 1 as Table 7 shows that paragraph one got the first rank with a mean of 4.51, and standard deviation of 0.77 . The highest percentage of $90.25 \%$ of respondents agrees was in paragraph 1 . It was sequentially followed by paragraphs 2,3 and 5 and Paragraph 4 ranked last with a mean of 3.58 and a standard deviation of 1.11. The overall average of the variable is 3.97 and the standard deviation is 0.77 with the degree of confidence at $79.54 \%$. The first two paragraphs have a very high degree, this means they are almost closed together, the last three paragraphs have a high degree, and the means are closed together.

\section{Hypothesis:}

The safety section was tested for the fourth hypothesis test, which statistically

Table 7. Descriptive statistics of safety.

\begin{tabular}{lcccc}
\hline \multicolumn{1}{c}{ Question number } & Mean & $\begin{array}{c}\text { Std. } \\
\text { Deviation }\end{array}$ & Rank & $\begin{array}{c}\text { Approval } \\
\text { Degree }\end{array}$ \\
\hline $\begin{array}{l}\text { 1) Helps in maintaining complete medication } \\
\text { information about the patient }\end{array}$ & 4.513 & 0.773 & 1 & Highly agree \\
$\begin{array}{l}\text { 2) Provide space to list all medications together } \\
\text { 3) Helps in giving patient appropriate medication }\end{array}$ & 4.379 & 0.889 & 2 & Highly agree \\
$\begin{array}{l}\text { 4) Reduce adverse drug events } \\
\begin{array}{l}\text { 5) Better guideline adherence through reminding } \\
\text { professionals of actions to be undertaken }\end{array}\end{array}$ & 3.702 & 1.128 & 4 & Agree \\
$\quad$ Average variable & 3.977 & 1.119 & 5 & Agree \\
$\quad$
\end{tabular}


said (we have evidence that the high adaption of IT (information technology) is supported with the safety of patient from medical errors), It was also clarified that the safety section was approved with an average of high degree 4.51 above the degree of neutrality that informs $2.59-3.39$.

Result:

The hypothesis was accepted and it was agreed that there was an impact by using the IT system on health care and that it was improved through patient safety.

\section{The fourth part of questioner, Obstacles:}

Table 8 shows the analysis of the standard methods and the degree of approval for each of the paragraphs in Part IV of the questionnaire. In this section, the analysis shows the respondents' view of the research towards the obstacles faced by Yemeni hospitals because of using the IT system.

Table 8 shows that most of the obstacles faced by Yemeni hospitals were of a high grade for paragraphs 1, 2. paragraphs 2 got the first rank with a mean of 3.55 , and standard deviation of 1.32 . The highest percentage $71.03 \%$ of respondents agrees. In paragraphs, 3,4 , and 5 obtained a moderate degree is the least influential. This means that the respondents in the research samples were at the level of neutrality with these obstacles. Paragraph 4 was ranked last with a mean of 2.705 and standard deviation of 1.17. The overall average of the variable is 3.12 and the standard deviation is 0.98 with the degree of confidence at $62.59 \%$.

The researcher pointed out that these obstacles are linked directly to the information technology system, and as the result showed previously, a high degree of respondents are working in hospitals without any other job.

\section{Reliability}

Reliability of a research instrument concerns the extent to which the instrument yields the same results on repeated trials. Although unreliability is always present to a certain extent, there will generally be a good deal of consistency in the results of a quality instrument gathered at different times. The tendency toward consistency found in repeated measurements is referred to as reliability. To determine the reliability and credibility of the data collection tool and the credibility of answers, the questionnaire was tested using Cronbach's Alpha to ascertain

Table 8. Descriptive statistics of obstacles.

\begin{tabular}{lccccc}
\hline \multicolumn{1}{c}{ Question number } & Mean & $\begin{array}{c}\text { Standard } \\
\text { deviation }\end{array}$ & Rank & Average & $\begin{array}{c}\text { Verbal } \\
\text { appreciation }\end{array}$ \\
\hline 1) Available computers not suitable & 3.420 & 1.275 & 2 & $68.39 \%$ & Agree \\
2) Available computers not enough & 3.552 & 1.324 & 1 & $71.03 \%$ & Agree \\
3) System interface not comfortable & 3.131 & 1.194 & 3 & $62.63 \%$ & Neutral \\
4) System impose additional work tasks & 2.705 & 1.179 & 5 & $54.11 \%$ & Neutral \\
5) System need long time to be learned & 2.859 & 1.210 & 4 & 57.17 & Neutral \\
$\quad$ Average & 3.129 & 0.984 & & $62.59 \%$ & Neutral \\
\hline
\end{tabular}


the extent of the stability of the questionnaire and the sincerity of the views of a sample. Table 9 shows the results of Cronbach's Alpha test to all the questions of the questionnaire.

As stated in Table 9 the value of the reliability coefficient for the data collection tool (questionnaire) came up $80.5 \%$ and this means that the stability is very good.

\section{Correlation Analysis}

According to Sekaran, in doing any study project which has several variables, further than knowing the means and standard derivation of the variables, the researcher would often like to recognize how one variable is related to another. Inter-correlation analysis indicates the nature, direction, and significance of the bivariate relationship of the variables used in the study.

This study concludes examines the nature of the relationship that exists between independent and dependent variables. To determine the relationship between the variables, person correlation was run between the variables, and a perfect positive correlation was found between two variables, which is represented by 1.0 (plus 1), or a perfect negative correlation which would -1.0 (Minus 1) as shown under Figure 2. Whereas, the correlation might range between -1.0 and +1.0 , the researcher conducted this study to know if any correlation found between two variables is significant or not (i.e.; if it has occurred solely by chance or if there is a high probability of its actual existence). As for the information, a significance of $\mathrm{p}=0.05$ is the generally accepted conventional level in social sciences research.

Davis (1997) projected the rules of thumb that need to be used in interpreting the R-value obtained from intercorrelation analysis as shown in Table 10.

Table 11 illustrates the correlation matrix between the major variables. The relationship between variables was tested using Pearson's correlation coefficient.

\section{Conclusion}

The respondents were divided according to the demographic variables. In addition,

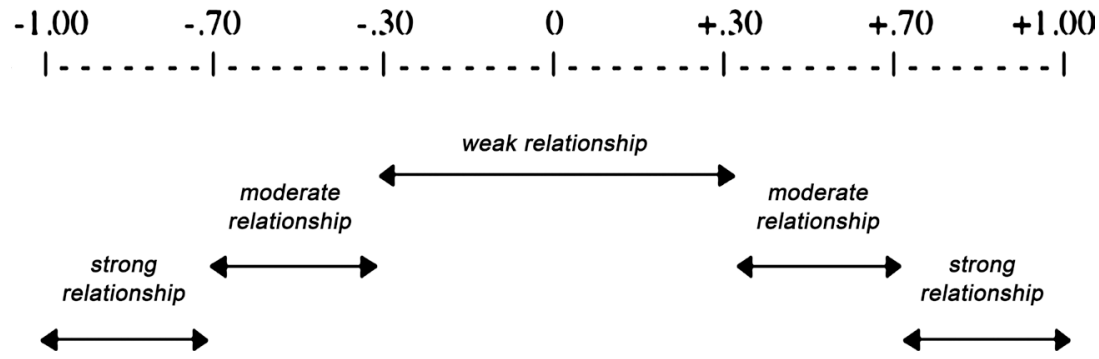

Figure 2. Interpreting correlation data.

Table 9. Cronbach's Alpha.

\begin{tabular}{ccc}
\hline Variables & Cronbach's Alpha & Number of items \\
\hline All variables & 0.805 & 34 \\
\hline
\end{tabular}


Table 10. Interpreting the R-value for inter correlations.

\begin{tabular}{cc}
\hline R-value & Relationship \\
\hline Above 0.70 & Very strong relationship \\
$0.50-0.69$ & Strong relationship \\
$0.30-0.49$ & Moderate relationship \\
$0.10-0.29$ & Low relationship \\
$0.01-0.09$ & Very low relationship \\
\hline
\end{tabular}

Table 11. Correlation analysis.

\begin{tabular}{|c|c|c|c|c|c|c|c|}
\hline & & $\begin{array}{c}\text { Adoption } \\
\text { level }\end{array}$ & Time & Effort & Cost & Safety & Obstacles \\
\hline \multirow[t]{3}{*}{ Adoption level } & Pearson Correlation & 1 & 0.060 & 0.024 & $0.204^{\star *}$ & $0.334^{* *}$ & -0.014 \\
\hline & Sig. (2-tailed) & & 0.239 & 0.634 & 0.000 & 0.000 & 0.791 \\
\hline & $\mathrm{N}$ & 389 & 388 & 387 & 381 & 380 & 380 \\
\hline \multirow[t]{3}{*}{ Time } & Pearson Correlation & 0.060 & 1 & $0.817^{\star *}$ & $0.508^{\star *}$ & $0.466^{* *}$ & 0.046 \\
\hline & Sig. (2-tailed) & 0.239 & & 0.000 & 0.000 & 0.000 & 0.361 \\
\hline & $\mathrm{N}$ & 388 & 398 & 397 & 391 & 390 & 389 \\
\hline \multirow[t]{3}{*}{ Effort } & Pearson Correlation & 0.024 & $0.817^{\star *}$ & 1 & $0.481^{\star *}$ & $0.439^{* *}$ & 0.049 \\
\hline & Sig. (2-tailed) & 0.634 & 0.000 & & 0.000 & 0.000 & 0.338 \\
\hline & $\mathrm{N}$ & 387 & 397 & 397 & 391 & 390 & 389 \\
\hline \multirow[t]{3}{*}{ Cost } & Pearson Correlation & $0.204^{\star *}$ & $0.508^{* *}$ & $0.481^{\star *}$ & 1 & $0.693^{* *}$ & $0.143^{\star *}$ \\
\hline & Sig. (2-tailed) & 0.000 & 0.000 & 0.000 & & 0.000 & 0.004 \\
\hline & $\mathrm{N}$ & 381 & 391 & 391 & 399 & 398 & 396 \\
\hline \multirow[t]{3}{*}{ Safety } & Pearson Correlation & $0.334^{\star *}$ & $0.466^{* *}$ & $0.439^{\star *}$ & $0.693^{\star *}$ & 1 & $0.171^{\star *}$ \\
\hline & Sig. (2-tailed) & 0.000 & 0.000 & 0.000 & 0.000 & & 0.001 \\
\hline & $\mathrm{N}$ & 380 & 390 & 390 & 398 & 398 & 396 \\
\hline \multirow[t]{3}{*}{ Obstacles } & Pearson Correlation & -0.014 & 0.046 & 0.049 & $0.143^{\star *}$ & $0.171^{\star *}$ & 1 \\
\hline & Sig. (2-tailed) & 0.791 & 0.361 & 0.338 & 0.004 & 0.001 & \\
\hline & $\mathrm{N}$ & 380 & 389 & 389 & 396 & 396 & 398 \\
\hline
\end{tabular}

the dependent and independent variables were discussed separately, in addition to the statistical analysis of all the sample of the research. Thus, the IT system positively affects health care services having the following benefits: Saving (Time, Effort, and Cost), improving patient safety and quality of care, Increase efficiency, Decision supporting, and Increase patient and health workers satisfaction. Examples of each of these variables and their benefits that illustrate the positive effects of the use of information technology in the health care sector were illustrated and the correlation between the four variables indicated.

\section{Recommendations}

The study recommends that effective database must be strengthened to deliver services efficiently and improve the hospital performance. In this research, the necessary data were collected from the urban areas in the capital Sana'a. There- 
fore, the researcher recommends the adoption of the IT system in all health sectors in all Yemen hospitals and put it into an integrated system. Attention should be paid to the maintenance of electronic devices and websites periodically and to keep abreast of progress in this area in order to suit their use .The researcher also recommends attracting cadres specialized in the use of information technology system in addition to the rehabilitation of staff in hospitals through the holding of training courses on an ongoing basis with an explanation of the use of the electronic system. One of the most important recommendations is to connect all hospital departments with a single network system so that information is exchanged internally. Further research and studies on the use of the information technology system in the health care sector in different regions of Yemen are conducted. This facilitates the collection of data at any time and place. In addition to the provision and development of electronic payment methods in hospitals that apply the information technology system. Increasing the interest of the employees and achieving their satisfaction and supporting the achievements of the distinguished among them is of great importance in the eyes of the researcher. The government should be encouraged and supported in all Yemeni communities and provided the necessary facilities to adopt the IT system in all its functions. However, because of the war in Yemen and difficult situations such as power outages, some hospitals stopped using computers and papers were used to record data. Therefore, the researcher recommends facilitating the work of humanitarian organizations and providing the necessary electronic equipment instead of what caused by the war. Finally, the researcher recommends conducting further researches and studies on the use of the information technology system in the health care sector in different regions of Yemen.

\section{Conflicts of Interest}

The authors declare no conflicts of interest regarding the publication of this paper.

\section{References}

[1] Akadiri, O., Olusanya, A. and Omitola, O. (2009) Impact of Improved Telecommunication Services on Health Care Delivery in Nigerian Teaching Hospitals a Survey of Opinions. Journal of Information Technology, 9, 125-134.

[2] Idowu, B., Ogunbodede, E. and Idowu, B. (2003) Information and Communication Technology in Nigeria: The Health Sector Experience. Journal of Information Technology Impact, 3, 69-76.

[3] Schweiger, A., Sunyaev, A., Leimeister, J. and Krcmar, H. (2007) Information Systems and Healthcare XX: Toward Seamless Healthcare with Software Agents. Communications of the Association for Information Systems, 19, 692-709.

[4] Kostagiolas, P. and Zimeras, S. (2008) Enhancement of Hospital Libraries and Information Services through an e-Support System for Lifelong Learning Quality Methodologies and Tools. International Journal of Education and Information Technologies, 2, 132-137. 
[5] Bennani, A., Belalia, M. and Oumlil, R. (2008) As a Human Factor, the Attitude of Healthcare Practitioners Is the Primary Step for the Health: First Outcome of an Ongoing Study in Morocco. Communications of the IBIMA Journal, 3, 28-34.

[6] Clemensen, J., Rasmussen, J., Denning, A. and Craggs, M. (2011) Patient Empowerment and New Citizen Roles through Telehealth Technologies. The Third International Conference on Health, Telemedicine, and Social Medicine, Gosier, 23-28 February 2011, 114-119.

[7] Jæger, J. and Monteiro, E. (2005) Realizing Organizational Benefits with ICT in Healthcare: The Challenge of Integration. Proceedings of Conference Continuity of Care, Trondheim, 26-28 September 2005, 11 p.

http://www.idi.ntnu.no/ ericm/challenge_of_integration.pdf

[8] Byrnes, F. (2009) Define Healthcare Systems. Article Doctor: Health and Fitness Articles.

http://www.articledoctor.com/healthcaresystems/define-healthcare-systems-752

[9] World Health Organization (WHO) (2007) Everybody's Business. Strengthening Health Systems to Improve Health Outcomes: WHO's a Framework for Action. http://www.who.int/healthsystems/strategy/everybodys_business.pdf

[10] Eide, H., Eide, E., Kristjansdottir, O. and Dulmen, S. (2010) Mobile Health Care and Health Behavior Change-Development of a System for Virtual Counseling Based on Written Diary Questionnaires and Situational Feedback. Proceedings of the International Conference on Universal Technologies, Oslo, 19-20 May 2010, 1-13.

[11] Taneva, S. and Law, E. (2007) Interfacing Safety and Communication Breakdowns: Situated Medical Technology Design. In: Proceedings of the 12 th International Conference on Human-Computer Interaction, Springer-Verlag, Berlin, Heidelberg, 525-534.

[12] World Health Organization (WHO) (2004) STRATEGY 2004-2007: e-Health for Health-Care Delivery. http://www.who.int/entity/eht/en/eHealth_HCD.pdf

[13] Suomi, R. (2000) Leapfrogging for Modern ICT Usage in the Health Care Sector. Proceedings of the Eighth European Conference on Information Systems, Vienna, 1269-1275.

[14] Viitanen, J.A. (2009) User-Centred Approach to Healthcare ICT Development. Helsinki University of Technology, Department of Computer Science and Engineering, Espoo, 93 p. http://www.soberit.hut.fi/T-121/shared/thesis/lic_thesis_Viitanen.pdf

[15] Kahn, J., Yang, J. and Kahn, J. (2010) Mobile' Health Needs and Opportunities in Developing Countries. Health Affairs, 29, 252-258.

https://doi.org/10.1377/hlthaff.2009.0965

[16] Omary, Z., Lupiana, D., Mtenzi, F. and Wu, B. (2010) Analysis of the Challenges Affecting E-Healthcare Adoption in Developing Countries: A Case of Tanzania. International Journal of Information Studies, 2, 38-50.

[17] Marrow, P. (2008) An Industrial Perspective on Future ICT in Hospitals. http://www.comp.lancs.ac.uk/computing/research/cseg/projects/ideal/workshop/M arrowPaper.pdf

[18] Kapur, S. (2001) The Internet: Its Role in Medicine and Healthcare. Indian Academy of Clinical Medicine Journal, 2, 133-138.

[19] Gupta, M. (2006) ICT and Healthcare-Challenges and Opportunities. http://archive.eurescom.eu/activities/pdfs/Eurescom_Stimulus_Paper_ICT_and_He althcare.pdf

[20] Sackmann, S., Eymann, T. and Muller, G. (2002) EMIKA Real-Time Controlled 
Mobile Information Systems in Health Care Applications. In: Proceedings of the Second Conference on Mobile Computing in Medicine, Edition Lecture Notes in Informatics, Heidelberg, 151-158.

[21] Gagnon, M., Légaré, F., Labrecque, M., et al. (2009) Interventions for Promoting Information and Communication Technologies Adoption in Healthcare Professionals. Cochrane Database of Systematic Reviews, No. 1, CD006093. https://doi.org/10.1002/14651858.CD006093.pub2

[22] Cripps, H. and Standing, C. (2011) The Implementation of Electronic Health Records: A Case Study of Bush Computing the Ngaanyatjarra Lands. International Journal of Medical Informatics, 80, 841-848. https://doi.org/10.1016/j.ijmedinf.2011.09.007

[23] Fortin, J., Gagnon, M. and Lamothe, L. (2004) Evaluation of Health Care Information and Communication Technologies: A Framework to Support Decision Making. Proceedings of the IADIS International Conference e-Society, Avila, 16-19 July 2004, 517-525.

[24] Igira, F., Titlestad, O., Lungo, J., et al. (2007) Designing and Implementing Hospital Management Information Systems in Developing Countries: Case Studies from Tanzania Zanzibar. Health Informatics in Africa (HELINA).

https://www.academia.edu/17298145/Designing_and_implementing_hospital_manag ement_information_systems_in_developing_countries_case_studies_from_TanzaniaZanzibar

[25] Malik, M. and Khan, H. (2009) Understanding the Implementation of an Electronic Hospital Information System in a Developing Country: A Case Study from Pakistan. Proceedings of Third Australasian Workshop on Health Informatics and Knowledge Management, CRPIT, Wellington, Vol. 97, 31-36. http://crpit.com/confpapers/CRPITV97Malik.pdf

[26] So, E.-Y. and Park, H.-A. (2011) Exploring the Possibility of Information Sharing between the Medical and Nursing Domains by Mapping Medical Records to SNOMED CT and ICNP. Health Information Research, 17, 156-161. https://doi.org/10.4258/hir.2011.17.3.156

[27] Sequist, T., Cook, D., Haas, J., et al. (2008) Moving Health Information Technology Forward. Journal of General Internal Medicine, 23, 355-357. https://doi.org/10.1007/s11606-008-0551-y

[28] Eason, K. (2009) Information Systems in Health Care-Breaking down Barriers or Creating More. Proceeding of Conference Dilemmas for Human Services. Breaking down the Barriers 13th International Research Conference, Staffordshire, 10-11 September 2009.

[29] Nicola, M. and Jarke, M. (1998) Design and Evaluation of Wireless Health Care Information Systems in Developing Countries. Proceedings of the IFIP Conference: Implementation and Evaluation of Information Systems in Developing Countries, Bangkok, February 1998.

[30] Harrison, J. and Lee, A. (2006) The Role of E-Health in the Changing Health Care Environment. Nursing Economics, 24, 283-289.

[31] Alpay, L., Toussaint, P. and Zwetsloot-Schonk, B. (2004) Supporting Healthcare Communication Enabled by Information and Communication Technology: Can HCI and Related Cognitive Aspects Help. Proceedings of the Conference on Dutch Directions in HCI, Amsterdam, June 2004, 12-16.

[32] Atherton, H., Huckvale, C. and Car, J. (2010) Communicating Health Promotion and Disease Prevention Information to Patients via Email: A Review. Journal of Te- 
lemedicine and Telecare, 16, 172-175. https://doi.org/10.1258/jtt.2010.004002

[33] Dixit, R., Choudhary, S. and Bansal, B. (2008) E-Health: Emerging ICT, Implementation and Provisioning Issues in Health Care Services. Proceedings of the National Conference on Advancements in Information Technology \& Communication Technology, Allahabad, 15-16 March 2008.

[34] Meingast, M., Roosta, T. and Sastry, S. (2006) Security and Privacy Issues with Health Care Information Technology. Proceedings of 28 th Annual International Conference of the IEEE Engineering in Medicine and Biology Society, New York, August 2006, 5453-5458. https://doi.org/10.1109/IEMBS.2006.260060

[35] Holyroyd-Leduc, J., Lorenzetti, D., Straus, S., et al. (2011) The Impact of the Electronic Medical Record on Structure, Process, and Outcomes within Primary Care: A Systematic Review of the Evidence. Journal of the American Medical Association, 18, 732-737.

[36] World Health Organization (WHO) (2011) Global Observatory for e-Health Series Volume 3, m Health: New Horizons for Health through Mobile Technologies. http://whqlibdoc.who.int/publications/2011/9789241564250_eng.pdf 